\title{
Addressing the Risk of Product Fraud: A Case Study of the Nigerian Combating Counterfeiting and Sub-Standard Medicines Initiatives
}

\author{
Spink J ${ }^{* 1}$, Moyer $\mathrm{DC}^{2}$ and Rip $\mathrm{MR}^{3,4}$ \\ ${ }^{1}$ Director and Assistant Professor, Food Fraud Initiative, Michigan State University, United States \\ ${ }^{2}$ Assistant Professor, Program in Public Health, Michigan State University, United States \\ ${ }^{3}$ Director and Assistant Professor, Global Initiatives, Division of Public Health, Michigan State University, United \\ States \\ ${ }^{4}$ Assistant Professor, School of Criminal Justice, Michigan State University, United States
}

${ }^{*}$ Corresponding author: Spink J, Director and Assistant Professor, Food Fraud Initiative, Michigan State University, United States, E-mail: spinkj@msu.edu

Citation: Spink J, Moyer DC, Rip MR (2016) Addressing the Risk of Product Fraud: A Case Study of the Nigerian Combating Counterfeiting and Sub-Standard Medicines Initiatives. J Forensic Sci Criminol 4(2): 201

Received Date: December 22, 2015 Accepted Date: April 26, 2016 Published Date: April 27, 2016

\begin{abstract}
Combating counterfeit medicines requires a new and unique crime scene investigation and forensic science approach. The "crime scene" is both at the production of the counterfeit product anywhere in the world and simultaneously at the packaged product in a consumer's hand. The focus of this paper is the application of criminology theory for prevention of counterfeit medicine risk. While focusing on prevention is not new for the criminology and public health disciplines, it is new with respect to product counterfeiting. It is novel to apply Crime Science theory to a public health challenge. The World Health Organization has specifically defined the scope to include substandard/ spurious/ falsely-labeled/ falsified/ counterfeit medical products (SSFFC or "suff-ick"). A methodology was developed to consider strategic countermeasures based on Situational Crime Prevention which includes the Routine Activities Theory and the Crime Triangle. The Nigerian SSFFC initiatives were used as a case study to apply this theory. The insights are applicable to reducing the public health risk of SSFFC in other countries. This article is a case study with impact assessment that provides the foundation for application of a criminology theoretical perspective.
\end{abstract}

Keywords: Counterfeit; Fraud; Medicines; Nigeria; Situational Crime Prevention; Routine Activities Theory

\section{Introduction}

Combating counterfeit medicines requires a new and unique crime scene investigation and forensic science approach. The "crime scene" is both at the production of the counterfeit product anywhere in the world and simultaneously at the packaged product in a consumer's hand. The focus of this paper is the application of criminology theory for prevention of the counterfeit medicines risk. The prevention approach is the foundation of public health but it is beyond the current reactionary countermeasures being taken. A fundamentally different proactive approach is required for combating counterfeit medicines [1]. Unlike other public health risks, an important distinction is that counterfeiters are human actors rather than pathogens or other natural toxins. As such, they apply an intelligence to be clandestine, stealthy and actively seek to avoid detection. They intentionally defraud with no regard, knowledge, or concern of the public health risk. Understanding this challenge, re-framing the issue is consistent with the public health objective to prevent a disease rather than just treating the symptoms.

The research goal is to develop a crime scene investigation and forensic science model to understand and combat counterfeit medicines. This is accomplished by applying Situational Crime Prevention theory which includes Routine Activities Theory and the Crime Triangle. Current public health research on counterfeits and substandard medicines ${ }^{1}$ focuses on the quantity of illicit medicines, the quality of all the medicines, or on the development of detection techniques [2,3]. The traditional approach to combating counterfeit medicines is rapid intervention and response. But even if speed and accuracy continue to improve, this approach is not fast enough to prevent counterfeiting and protect the public's health.

${ }^{1}$ Consistent with the WHO and most often with the US FDA, the term "medicine" is used to cover prescription and over-the-counter medicines. The terms "drugs" and "illegal drugs" are not used since they can be confused with traditional illicit street drugs such as cocaine and heroin. 
The Nigerian combating counterfeit medicines initiative was used as a case study to demonstrate this behavioral sciences and criminology approach. Specifically this applies the Nigerian layered and multi-faceted initiatives combating counterfeit and substandard medicines from 2001 through 2012. Nigeria has been proactive and various countermeasures have been studied by groups such as the World Health Organization (WHO) in reports that are referenced throughout this article. The Nigerian National Agency for Food and Drug Administration and Control (NAFDAC) has been recognized globally as achieving progress through innovative, interdisciplinary countermeasures that have been applied with persistence and diligence [4,5]. Because Nigeria is an excellent case study due to the economic growth opportunities (regarded by some as the biggest economy in Africa [6,7], the government focus on anti-corruption and combating counterfeit medicines, and the exposure from the implementation of the initiatives, the concepts apply to other countries. This article provides a case study with impact assessment that provides the foundation for application of a criminology theoretical perspective.

\section{Materials and Methods}

This research project reviewed current literature on counterfeit medicines that specifically addressed the situation in Nigeria. Nigerian government presentations, and related articles, were the sources of the current combating counterfeit medicines initiative.

\section{Background}

Counterfeit medicines are a global risk to public health in both developed and developing countries [3,8-17]. Major anticounterfeiting efforts are underway by groups such as the World Health Organization (WHO), U.S. Pharmacopeia (USP), Interpol, U.S. Food and Drug Administration(FDA), as well as other governmental and non-governmental organizations. Examples of incidents that compromised the public's health include:

- "During a meningitis epidemic in Niger in 1995, more than 50000 people were inoculated with fake vaccines resulting in 2500 deaths. The vaccines were received as a gift from a country which thought they were safe.

- 89 children died in Haiti in 1995 and 30 infants died in India in 1998 due to the consumption of paracetamol cough syrup prepared with diethylene glycol (a toxic chemical used in antifreeze).

- In 2001, in South-East Asia, a Wellcome Trust study revealed that 38\% of 104 anti-malarial drugs on sale in pharmacies did not contain any active ingredients.

- In Cambodia, in 1999, at least 30 people died after taking counterfeit anti-malarials prepared with sulphadoxine-pyrimethamine (an older, less effective anti-malarial) which were sold as artesunate" [3].

There are two main risks which include counterfeit and substandard medicines [8,14]. Counterfeits are "medicines that are deliberately and fraudulently mislabeled with respect to identity and/or source" [3]. Sub-standards are medicines "problems with the manufacturing process by a known manufacturer" [3]. Expanding to include other vulnerabilities, the WHO has specifically defined the scope to include substandard/ spurious/ falsely-labeled/ falsified/ counterfeit medical products (SSFFC or "suff-ick") $[8,14]$.

Governmentalled public health initiatives have broadened to cover SSFFC products beyond simple trademark, patent, or intellectual property rights counterfeiting. These broader issues include date code compliance (i.e. efficacy expired products) and stolen goods among others. While these products are not counterfeit, they are knowingly inserted in the supply chain fraudulently for profit [18]. In many countries such as the U.S., the definition of counterfeit product includes intellectual property rights violation such as unauthorized use of trademarks or patents including bioequivalent generic products [19-21]. Government initiatives must be broader because countermeasures have to consider fraudsters ${ }^{2}$. These include criminals that are not concerned with breaking laws and sociopaths that are not concerned with cheating consumers. Additionally fraudsters are not fully aware of, or concerned by, the complex and potentially hazardous nature of ingredient interaction [32,33].

There are no precise statistics on the prevalence of SSFFC medicines. It has been well documented that even the most formal reports quantifying their economic impact and scale are based on estimates or guesses [34,35]. The global estimate of SSFFC ranges from $10-90 \%$ of all medicines, depending on geographic region [3,14]. The SSFFC rate - which includes some forms of genuine but fraudulent product - is frequently above $90 \%$ in developing countries and approximately $10 \%$ in developed countries such as the U.S. and Western Europe [15]. In general, the WHO estimates that western markets have a counterfeit medicine rate of $1-3 \%$ [3].

The discipline of anti-counterfeit strategy is rapidly developing and evolving to not only keeps up with effective intervention and response, but to also shift to prevention [36,37]. This shifts away from the goal of catching counterfeits and replaces it with the intention to drive fraudsters out of the system - or deters them from entering it in the first place. This is reflected by a shift from reactionary tactics to proactive strategic countermeasures in companies and countries that are facing more complex and risky threats.

${ }^{2}$ While fraudster may seem to be a casual term, it is broad enough to cover all aspects of SSFFC. This term is used in many formal documents such as by the U.S. Federal Bureau of Investigation among others [21-31]. 
While there have been many specialized research projects and initiatives regarding intellectual property rights, product adulteration, authentication and traceability technology, and product quality, there have been few attempts to holistically understand the root cause of the problem, that being the fraud opportunity. The proactive approach to the problem can be achieved by shifting the research focus to the motivations of the human actors committing these frauds. To understand the factors that could be manipulated to prevent or reduce the fraud opportunity this research employed the concept of the Situational Crime Prevention and the Routine Activities Theory of the Crime Triangle [38-40].

\section{Criminology}

A key to addressing counterfeit and deliberate substandard medicines is to prevent the crime in the first place. The role of enforcement and prosecution in deterrence is complex and clearly supported by criminology theory [39-44]. The benefits are to reduce the scale of the fraud, keep law-abiding citizens law-abiding, clearly define that the activity is illegal, and stigmatize the act - to define that counterfeiting is clearly illegal and wrong.

A criminology theory that directly supports crime prevention is Situational Crime Prevention including Routine Activities Theory. This defines a set of factors that are necessary for a crime to occur. An emphasis on Situational Crime Prevention enables authorities to anticipate the conditions that create counterfeiting opportunities or fraud opportunities [29]. This focus further enables the selection of effective etection and deterrence strategies [45]. This distinguishes proactive actions that can prevent or inhibit the fraud opportunity from reactive actions that simply increase the speed or accuracy of identifying and confiscating counterfeit products.

It is outside the scope of this research to review the theoretical application of criminology theories such as guardianship. The applications of those theories have generally been extensively covered as well as specifically for related product counterfeiting $[19,23,40,41,46-49]$.

A key Situational Crime Prevention concept is Routine Activities Theory and the Crime Triangle that is used to understand the nature of the fraud and the fraudsters to determine effective countermeasures (Figure 1) [32,50-52]. Traditionally - and admittedly taking the best of several theories -- the elements or sides of the Crime Triangle are comprised of: (1) a victim, (2) a criminal, and (3) opportunity that is enabled by the absence of a capable guardian. The area within the triangle represents the magnitude of the crime opportunity. The Crime Triangle is adapted to general fraud terms of (1) victim, (2) fraudster, and (3) guardian and hurdle gaps $^{3}$ with the area of the triangle representing the fraud opportunity. The following briefly describes the four components of the Crime Triangle. These terms have been adapted from the traditional criminology approach to counterfeit medicines.



Figure 1: The Crime Triangle Which Deconstructs the Fraud Opportunity of Counterfeit Medicines (Adapted by Spink from [40,41])

- Victim: This element of the triangle is comprised of all entities that are attacked or defrauded. This includes not only consumers but also tax collectors, retailers, wholesalers, and brand owners. As brands become stronger, more recognized and more preferred by consumers around the world, the "victim" element of the fraud opportunity will continue to grow. The growing consumer confidence in brands will also support social harmony and increase the consumer confidence in the market and government. The goal is not to reduce the consumer preference. Reducing the vulnerability of the victim would be in the "guardian and hurdle gaps" leg of the triangle.

${ }^{3}$ The "criminal" term is adapted to fraudster and "absence of a capable guardian" is adapted to guardian and hurdle gaps, and the area within the triangle is adapted to the fraud opportunity. 
- Fraudster: This element of the triangle includes the entity that commits the fraudulent act. This is a human actor (or organization) that is clandestine, stealthy, and actively seeking to evade detection. In some cases it may be erroneous to include all perpetrators in this general identification as some actions may not be illegal or a crime (e.g., un-registered trademarks or patents). This is a very important focus for governments and companies but this is not a single solution. As with many types of crimes, there are an unlimited number of potential criminals and fraudsters. Understanding and combating the criminal or fraudster is important in relation the overall goal of prevention and reducing the fraud opportunity.

- Guardian and Hurdle Gaps: This is the element that includes the guardians who monitor and protect the product. This can include customs officials, federal and local law enforcement, trade associations, non-governmental organizations, individual companies themselves, or even consumers. Hurdles are the components or systems that exist, or are put in place, to make counterfeit fraud more difficult to perpetrate. Even complex webs of different guardians and hurdles can have gaps that are exploited by fraudsters. While there may be capable guardians and hurdles at one point, the evolving nature of the marketplace and the adaptability of counterfeiters create new gaps [33,53-56].

- The Fraud Opportunity: In summary, the three sides of the triangle surround the fraud opportunity. The goal is to reduce the area of the triangle, and reduce the fraud opportunity.

It is important to understand the different types of counterfeits, counterfeiters, and counterfeiting organizations before selecting effective countermeasures [53,54]. Consideration of these concepts also increases the understanding of how and why fraudsters circumvent laws, audits, and certifications [53,54].

\section{Nigeria}

While Nigeria probably has one of the highest recorded quantity of SSFFC medicines incidents within Sub-Sahara Africa, that analysis is based on the intensive investigations of counterfeit cases and articles seized, as well as being one of the largest economies in the region (by some estimates, the largest in Africa [6,7]. As such, even a small percentage of counterfeit products would equate to comparatively high quantities of seizures. Additionally, increased enforcement action often highlights the extent of a problem whereas some countries simply do not look for counterfeits. Nigeria's large scale and consistent enforcement actions have contributed to the relatively high number of reported incidents compared to other less defended markets. Among the many reports of NAFDAC activities and seizures include a 2004 raid that found 3,000 unregistered medicine outlets. Another NAFDAC raid in 2008 was made on a large market that resulted in a seizure of 80 truckloads of counterfeit medicines [57]. For their advancement against this public health risk, the NAFDAC has been recognized as a world leader in the fight against counterfeits and sub-standard medicines [4].

Nigerian anti-counterfeiting countermeasures began in 2000 and continue to evolve through 2015. NAFDAC accomplishments have reduced the proportion of counterfeits in the pharmaceuticals market from about 67\% in 2001 to 16\% in 2004 [58-60]. Also, unregistered drugs (i.e. genuine but not been cleared by NAFDAC for importation) declined from 68\% to 19\% [60]. In early 2012, NAFDAC reported an ongoing nationwide survey of over 2,700 medicine samples disclosed that $10 \%$ were counterfeit or substandard [61]. Later in 2012, NAFDAC noted a reduction to about 5\% and a sample size now exceeding 6,000 [62].

While the progress is significant, Nigeria's public health remains at risk. Surveys indicate that counterfeit and substandard medicines are still widely distributed. A 2011 study, based on data collected from Nigeria in 2009, found medicines in Lagos to be $19 \%$ counterfeit or substandard ${ }^{4}$ [64]. A 2011 WHO report of anti-malarial medicines in six African Countries, including Nigeria, of survey data obtained in 2008, revealed over $23 \%$ of 198 tested Nigerian anti-malarials were sub-substandard ${ }^{5}$ [65]. A 2012 study of counterfeit medicines in Lagos found a "statistically significant drop in the number of drugs failing quality control tests" [66]. Although the risk from counterfeit medicine remains, the overall decrease and will result in diminishing the adverse effects on human health.

\section{Summary}

It should reasonably be anticipated that any refinement in countermeasures or detection processes will be met with fraudsters' own countermeasures. An anti-counterfeit strategy should be dynamic and not be perceived as leading to ultimately "fixing" something. To provide an anecdote: preventing counterfeiting is more akin to managing a chronic disease such as diabetes rather than the one-time fix of an acute incident such as a broken leg.

\section{Results and Discussion}

The Nigerian fight against SSFFC medicines has included many initiatives from 2001 through 2012. The government-funded $^{7}$ initiatives are logical from a financial return-on-investment approach since they lead to expanded tax revenue from the growing economy and reduce the sale of counterfeits that evade taxation. To frame the overall scale of smuggling, it is estimated that Nigeria loses \$325 million per year due to customs evasion and non-payment of value-added-tax on smuggled textiles alone [67].

\footnotetext{
${ }^{4}$ This study focused on market pricing and sampled 899 products across 17 countries including 53 products from Lagos [63].

${ }^{5}$ For the products sampled from Nigeria, 200 samples were taken from five regions of the country (including 91 from the Lagos) and three marketing distribution channels.
}

${ }^{6}$ This study specifically reviewed the impact of the handheld Raman spectroscopy authentication tools.

${ }^{7}$ Pharmaceutical companies do buy government issued tax stamps or labels. 
The current counterfeit product initiative includes several actions and, while each should be considered by itself, the real value is how a holistic and all-encompassing approach created an integrated system. A multi-layered approach is critical where a limitation of a specification action may be neutralized by a benefit from another action. While the Crime Triangle was not proactively part of the NAFDAC analysis or decision-making process, it is an excellent tool to deconstruct the fraud opportunity and analyze impact of the countermeasures.

\section{Action 1: Product Authentication}

Product Authentication is a process for law enforcement or investigators to test product authenticity in-the-field, simultaneously from many locations, and with an immediate assessment of "authentic" or "suspicious." A field trial of the Thermo Scientific Incorporated Truscan $^{\mathrm{Tm}}$ handheld Raman Spectroscopy equipment was conducted in December 2009 and the system was implemented February 2010 (Figure 2). A tablet can be inserted into the port of this device to authenticate the product itself, rather than the product's packaging. It also has an attachment that can scan through clear packaging to the product. A chemical profile of the suspect product is created and compared with a pre-loaded genuine product profile to confirm authenticity.

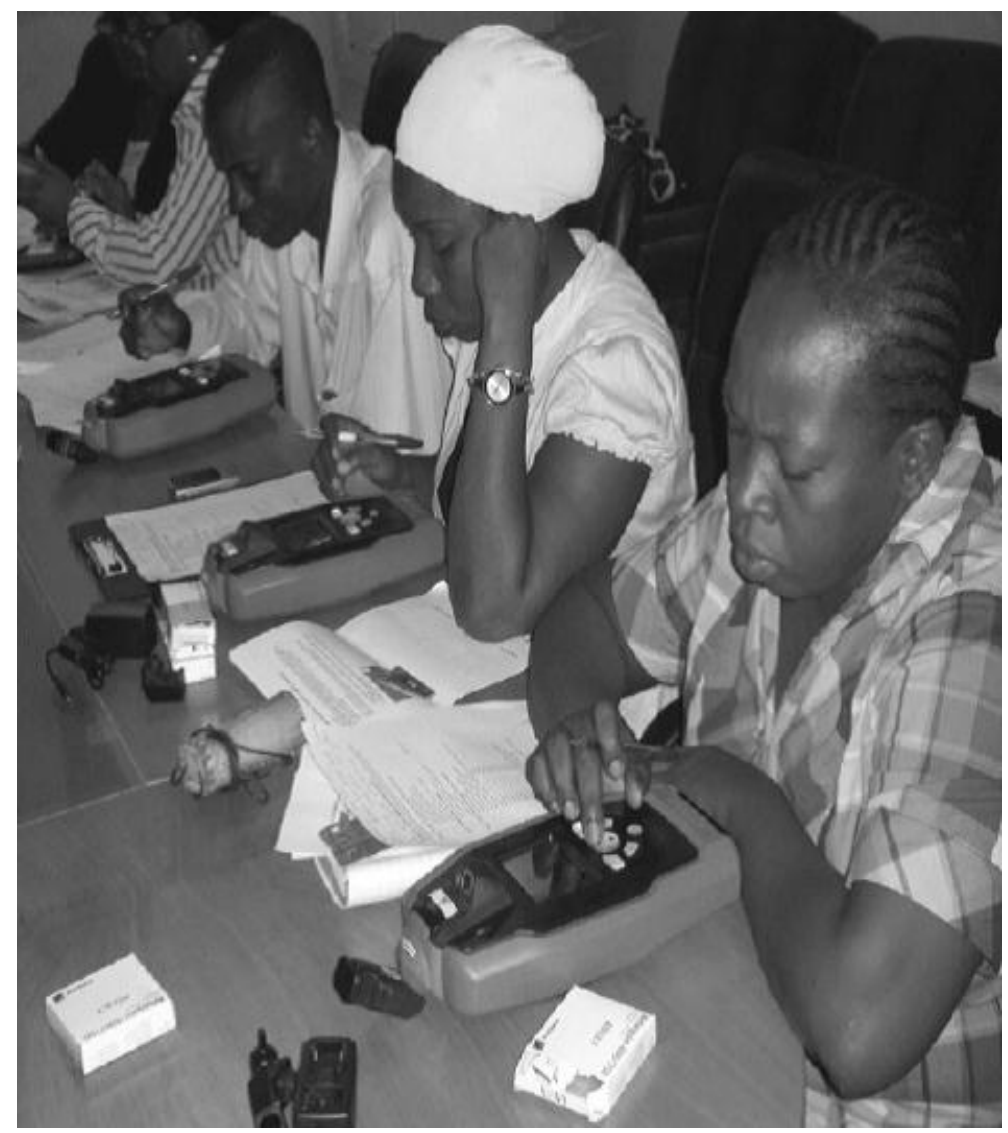

Figure 2: Thermo Scientific Incorporated $\operatorname{Truscan}^{\text {Tx }}$ handheld Raman Spectroscopy equipment (in use by NAFDAC counterfeit medicine inspectors) [17]

To support the authentication of the samples by the equipment, NAFDAC utilizes and updates the profiles of the products that are authorized and approved for sale in the marketplace. NAFDAC coordinates the update of the reference product profiles. The product profiles are test results from standard quality and authentication tests using internationally and publically available methods.

An immediate match can be confirmed by customs officials at borders, investigators in a wholesale warehouse, or in a retail marketplace. The initial response to the program was that more businesses asked to join the program, including importers, manufacturers, distributors, and pharmacists. The point-of-purchase analysis creates a situation where consumers could immediately confront sellers of identified SSFFC medicines [68]. A key benefit of this system is that it truly tests the actual product rather than a packaging component or feature.

Part of the effort to support enforcement, beyond the portable, handheld device mentioned, is the use of the lab equipment known as the Black Eye ${ }^{\mathrm{TM}}$ (a commercially available infrared technology) and the Global Pharmaceutical Health Fund Minilab Test Kits [16]. These are additional, more comprehensive, tests to further support rapid detection and enforcement. 
Discussion: Per the Crime Triangle, product authentication is a guardian and hurdle action intended to minimize the fraud opportunity. The Truscan device accomplishes this by immediately identifying fraudulent product. The Truscan system was implemented and is now used by government officials at borders and by the regulatory law enforcement authority in marketplaces. This enables sellers of fraudulent product to be immediately identified. This action supports ex parte seizure if it is felt that the product or suspects might disappear. It also creates immediate consumer awareness that a product is fraudulent and the retailer is not trustworthy. If retailers are unsuspecting receivers of the fake goods, they could take immediate action against their wholesalers or distributors. This check-and-balance both dissuades fraudulent retailers from fraud and assist legitimate retailers in resisting "willful blindness" fraud [69-71]. Other benefits of using the Truscan device is that test results are immediate (i.e. no delay in waiting for laboratory-based testing) and it can detect fraudulent packaging. This test equipment also eliminates subjective investigator opinion and judgment.

Limitations: There are some limitations of this action since this is still a new technology. To be admissible in court, the results must be validated by further lab testing and the testing equipment does not apply to all products. Because products are removed from packaging for testing, it is a destructive test and product cannot be returned to commerce. Lastly, the device has limited distribution and is only available to government investigators.

There is a risk that counterfeit product profiles could be hacked (e.g. unauthorized access) into the database of authorized product profiles. If this hacking occurs then an "official" test would incorrectly authenticate and approve a counterfeit product.

\section{Action 2: Consumer Serialized Codes}

Serialized codes are a process that enables consumers to immediately authenticate product through a component or code, on devices or systems that are already in commercial use. Serial codes were implemented in 2010 through labels that have a "scratch-off" feature revealing a code that consumers can check to authenticate the product [17]. The suppliers pay for and apply the labels. This action specifically uses Sproxil Incorporated technology (Figure 3). The tester, usually the consumer at the point-of-purchase, scratches off the label to reveal a code, and then submits it for authentication through a mobile phone text message. The consumer receives an immediate positive "OK" or negative "Fake - Don't Use" statement [17]. This is similar to the M-Pedigree program in Ghana [72] and to systems that are already implemented in 2010 by Nigerian companies such as BioFem (Mobile Anti-counterfeit System-MAS) [73]. The chain of custody or pedigree of the product is not, however, identified by the system. The serial number is one more piece of evidence that a product is authentic.

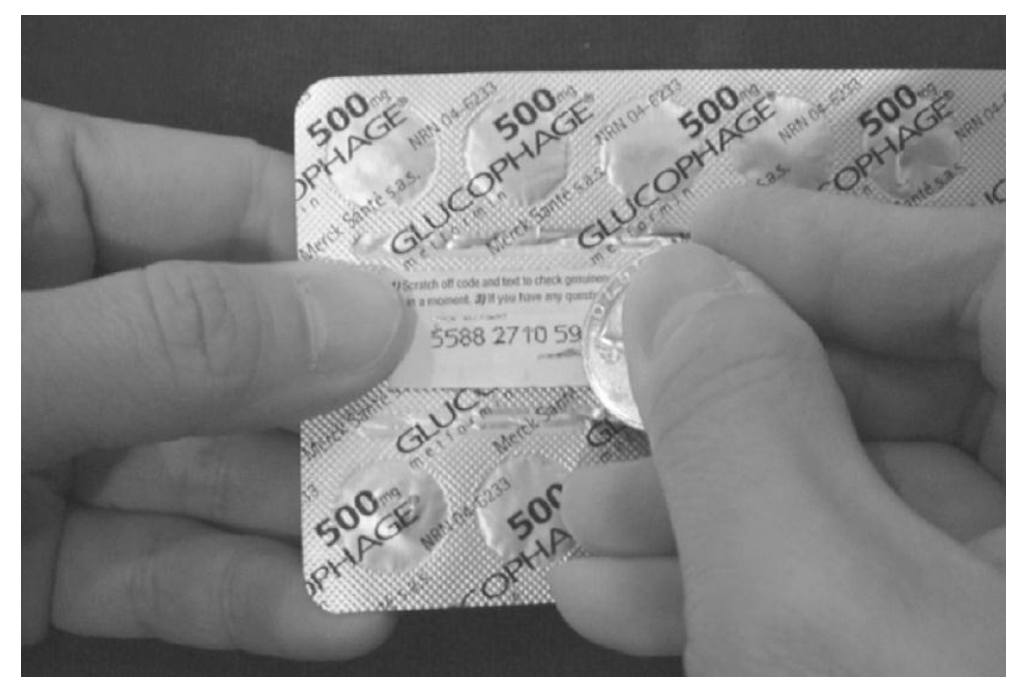

Figure 3: Picture of Sproxil technology Used in the Nigerian Anti-Counterfeit Initiative [17]

Discussion: Per the crime Triangle, consumer serialization codes address victims in order to minimize the fraud opportunity. This is accomplished be enabling the consumer to confirm the authenticity of their product at the point-of-purchase. In markets with a high prevalence of counterfeiting, consumers are willing, and do, authenticate frequently [74]. As with the Truscan system, this check-and-balance of immediate validation both dissuades fraudulent retailers from the crime and assist legitimate retailers in inadvertently engaging in fraud. A real validation of the business drivers for this system is that manufacturers and businesses initiated these programs to increase consumer confidence. Improved consumer confidence leads to increased sales for a company, brand, or retailer. This countermeasure does not provide track-and-trace or a product pedigree but it does authenticate the product through labeling. A key benefit of this system is that the central database can support a public health early warning system because it records when and where SSFFC products are identified.

Limitations: There are several limitations for the use of serialized consumer codes. Codes can only be used once. Consumers must have mobile phones and connectivity. The codes only authenticate the label on the package and not the actual product. The test is not available for wholesalers, distributors, or retailers due to the "scratch off" feature. 


\section{Action 3: Engage Source Economies}

Engaging source economies can reduce or inhibit the supply of illegal goods imported into the country. The NAFDAC is restricting the in-flow of counterfeit or substandard medicines by establishing contacts and programs with the governments of India and China, its largest importers of medicines [75-77]. Collaborative actions began during trade and health negotiations since 2009 include conducting pre-inspections before products are exported [78-80]. The engagement strategy has resulted in criminal convictions of counterfeiters in India and China [81].

Discussion: Per the crime Triangle, engaging source economies address fraudsters in order to minimize the fraud opportunity. This is accomplished by creating a more challenging and complex marketplaces for fraudulent manufacturers to produce, distribute, and sell their products. The core value of emphasizing and enforcing regulations between trade partners is that countries having legitimate companies are incentivized to reduce fraudulent exports [82].

Limitations: Engaging source economies as a fraud-reducing action has several limitations. Clandestine or smuggled product can still slip through the export and import detection and deterrence programs. While this countermeasure can reduce the total volume of SSFFC product being exported, it heavily relies on the efficacy and cooperation of the source countries. Inherently, this action does not address domestically produced products.

\section{Action 4: Support and Strengthen Enforcement}

Supporting and strengthening enforcement with more prosecutions and stronger punishment increases the deterrent effect for fraudsters [83]. Starting in 2009 public support for strengthening Nigeria's enforcement and prosecutions grew after the Chinese and Indian governments implemented life imprisonment sentences and death penalties for counterfeiters exporting to Nigeria $[81,84]$. Nigeria now has twelve laws directly relating to drugs, poisons, food control, product registration, and adulteration [85]. Regulations mandate that products must: be registered in the National Drug Formulary and Essential Drug List, meet safe product regulations and registration, be sold through registered dispensers, and be sold or made at registered retail outlets. Nigeria is also implementing tougher sentencing that includes life imprisonment and US Racketeer Influenced and Corrupt Organizations Act (RICO) type laws for seizure of assets [84]. There has been a media push to consider pharmaceutical counterfeiting at par with "drug trafficking" of illicit drugs such as cocaine and heroin [86]. Criminal prosecutions become a more effective deterrent as they are more vigorously pursued.

Discussion: Per the Crime Triangle, supporting and strengthening enforcement is a guardian and hurdle action intended to minimize the fraud opportunity. This is accomplished by creating a more challenging business environment for fraudsters. Rising enforcement and prosecution further encourages citizen support, increases consumer confidence in the medicine supply, and fosters trust in the government's ability to rectify the problem. Expanding the laws and regulations related to certification and registration provides more transparency of product and also benefits legitimate certified businesses.

Limitations: Supporting and strengthening enforcement for the deterrent value has limitations. Even prosecution that results in the seizure of counterfeit manufacturing equipment and the incarceration of criminals is not a total deterrent. The profit opportunity of counterfeiting is so great that there are a near unlimited number of potential criminals and fraudsters [33,34]. Enforcement resources are limited even in developed countries since there may be a lack of political will to support expanded funding enforcement. Citizen outrage including jury disposition may not produce fraud-deterring prison sentences. But any level of enforcement, even if in only confirms that the activity is illegal and has a potential of prosecution, is a deterrent for the law abiding citizens tempted by the profits of counterfeit medicines.

Also, there is still work to do on enforcement and prosecution within Nigeria. Relations with import partners were strained in 2009 following the seizure of a fake medicine consignment that was manufactured in China and fraudulently labeled as being made in India. This act led to six Chinese nationals being sentenced to death in 2009. The five Nigerians who were distributing the fake drugs received fines of only NGN500, 000 (US\$3,281) and were freed. "This reflects some of the issues that Nigeria has with its regulatory system and the failure to pass more stringent laws shows that there is still endemic corruption in the country" [76].

\section{Action 5: Regulate the Supply Chain}

Regulating the supply chain controls the distribution of authentic medicines, improves the quality of service, and also deters potential fraudsters. In 2009 there was a Nigerian focus is to strengthen its wholesale and retail medicine distribution system [87]. The initiative includes: (1) creating a central medicine distribution network of warehouses (Zonal Drug Distribution Center-ZDDC), (2) allowing only registered pharmacies to sell medicines, and (3) allowing only certified pharmacists to dispense product [75]. These actions create a well-defined "primary, traditional market" and also deter sellers who risk losing their certificates by knowingly selling counterfeit or substandard products. NAFDAC is considering even broader supply chain initiatives, such as the customs practice of "prior notice" for imports and other technologies, such as auto-identification for cargo shipments [88,89]. 
Discussion: Per the Crime Triangle, regulating the supply chain is a guardian and hurdle action intended to reduce the fraud opportunity. Better control of the supply chain simply establishes more structure for the transparent movement of product. Standard distribution nodes are more easily monitored and transparency reduces the gaps and opportunities where fraudulent product can enter the supply chain [90]. Additionally, consumers can build trust that they will not be defrauded by a primary outlet in a regulated supply chain. Establishing regulated ports of entry and authorized distribution centers has formalized the Nigerian supply chain and law-abiding citizens and businesses know where they can obtain legitimate products [91].

Limitations: The action of regulating the supply chain has limitations. There is still demand for low priced product by citizens who cannot afford the medicines available in the primary supply chain. While supply chains may be regulated, there is an ever-present potential for SSFFC product to enter them.

\section{Action 6: Retailer Product Authentication}

The NAFDAC has enabled retailer product authentication through "non-line-of-sight" technologies such as radio frequency identification (RFID) tagging. This action starting in 2010 adds another layer of authentication and transparency specifically for retailers and distributors. The goal of the system is to simply authenticate the tag itself with a battery-powered tool that does not require connection to a central database [92,93]. Medicine suppliers pay for and apply the tags and retailers, or consumers, purchase the pen-style readers that cost approximately $\$ 50$ each [92]. Although this initial system only authenticates tags, realtime access to full product pedigree data is possible with more powerful and technical RFID readers. Such systems will allow nonline-of-sight access to serialized authentication codes within sealed cartons, cases, or pallets of medicines. The NAFDAC plans to require this soon “once a large percentage of the nation's drugs are tagged" [93].

Discussion: Per the Crime Triangle, the retailer product authentication action addresses the retailer as a victim in order to reduce the opportunity for fraud and also engages the retailers as guardians monitoring the product. Retailers are enabled to authenticate product upon receipt or at point-of-purchase, leading to an additional layer of transparency. This is especially valuable in areas where there is no cellular phone coverage or wireless internet access to authenticate the consumer-serialized codes. It provides retailers with a way to conduct non-destructive product authentication tests. Other implemented actions are destructive and render the tested product unsalable (i.e. the Truscan product sampler and the Sproxil scratch-off label).

Limitations: The retailer product authentication action has several limitations. For example, the system is currently only available for distributors and retailers. Also, the system only authenticates the RFID label and not the package or product. The lack of connectivity to a central database creates two challenges. Updated codes may be slow to reach all markets and the authenticated codes were sent to a central database for analysis. In addition, there is more data management complexity since there will need to be a second set of authentication codes: on set for the consumers and one set for the retailers. Regardless of limitations, this action provides the retailer with non-destructive, economical, and fast authentication testing.

While the cost of the RFID tags have reduced to around 10 cents per tag [93], the tactic should be evaluated based on the local cost of medicines and cost of living. This per tag cost does not consider additional computer systems and management costs of a second set of serialized codes for the retailers. Even at 10 cents per tag the total cost is substantial. If Nigeria's 140 million citizens consumed ten pharmaceutical packages per year, this would equate to $\$ 140$ million in incremental packaging material costs per year. This estimate would be consistent with the manufacturer press-release stated up to 100 million tags per month would be sold to suppliers. It is estimated that over $90 \%$ of Nigerian citizens live below US $\$ 2$ per day so just one 10 cent tag equates to $5 \%$ of the daily wage. The medicines are already costly where a typical anti-biotic treatment costs 70\% of a daily wage [94]. In addition, the RFID readers cost $\$ 50$ for the estimated 3,000 retail outlets, or $\$ 150,000$ [92]. With the average family income is $\$ 2,300$, this $\$ 50$ would represent $2 \%$ of the annual income or a week's wages. Consumers' awareness of related fraud activity is already being demonstrated. For example, a consumer comment in a discussion board post from a trade journal article on the countermeasure asked, "What if the RFID pen is fake?" [95]. The unit costs of the tags and readers are significant considering the local cost of living and typical wages.

\section{Action 7: Consumer Awareness}

Increased consumer awareness of SSFFC medicines can reduce the number of consumers and patients who are defrauded. Since 2009 the NAFDAC has enabled both companies and citizens to become directly involved in the SSFFC medicine initiative including at the point-of-purchase [17]. The NAFDAC has been very visible with their actions through wide communications via the media. The NAFDAC has expanded awareness actions beyond the urban and economically thriving consumers to also include the more rural consumers and poorer regions. The NAFDAC considers the awareness initiative a work-in-progress.

Discussion: Per the Crime Triangle, the Nigerian consumer awareness initiative reduces the victim aspect of the opportunity since they are aware of counterfeits and also engages the consumer as a guardian. Both in the urban and rural areas, consumers are being educated on how to reduce the risks of counterfeit or substandard medicines. Increased consumer awareness as well as direct participation (e.g., consumer-authenticated serialized codes) further strengthens the initiative. More consumer awareness will provide real drivers for businesses to avoid fraudulent products and resist fraudulent activities. 
Limitations: The consumer awareness action has limitations such as literacy rates. The consumer awareness action is also challenged by limited communication in rural areas and generally lower levels of trust in the media and government.

\section{Priority of Countermeasures}

The strength of the anti-counterfeit strategy is that many components of the fraud opportunity are addressed. Some of the countermeasures are more direct and impactful (e.g., product and consumer authentication) whereas others are more system controls (e.g., engaging source economies and raising consumer awareness). Each countermeasure provides a unique, specific, and important role. The question should not be which countermeasure can be removed but what additional countermeasures further reduce the fraud opportunity. Additional contributing factors to the fraud opportunity are discussed later.

\section{Efficiency of the Integrated Actions}

This type of review is important to advance the understanding of the complex risks to public health and to reveal new effective anti-counterfeiting countermeasures. The NAFDAC SSFFC medicines initiative attacks the problem from many sides (Figure 4). This layered and multi-faceted approach, though not perfected or completed, reduces the fraud opportunity and disrupts the chemistry of the crime. Beyond just selecting and implementing countermeasures, the business and political climate in Nigeria has created financial incentives to support these actions [96]. NAFDAC continues to consider: potential countermeasures using criminology theory, the efficacy of implemented actions, and how the countermeasures can be further adapted to address evolving gaps. The potential for future fraud opportunity in Nigerian is discussed below using the framework of the Crime Triangle.

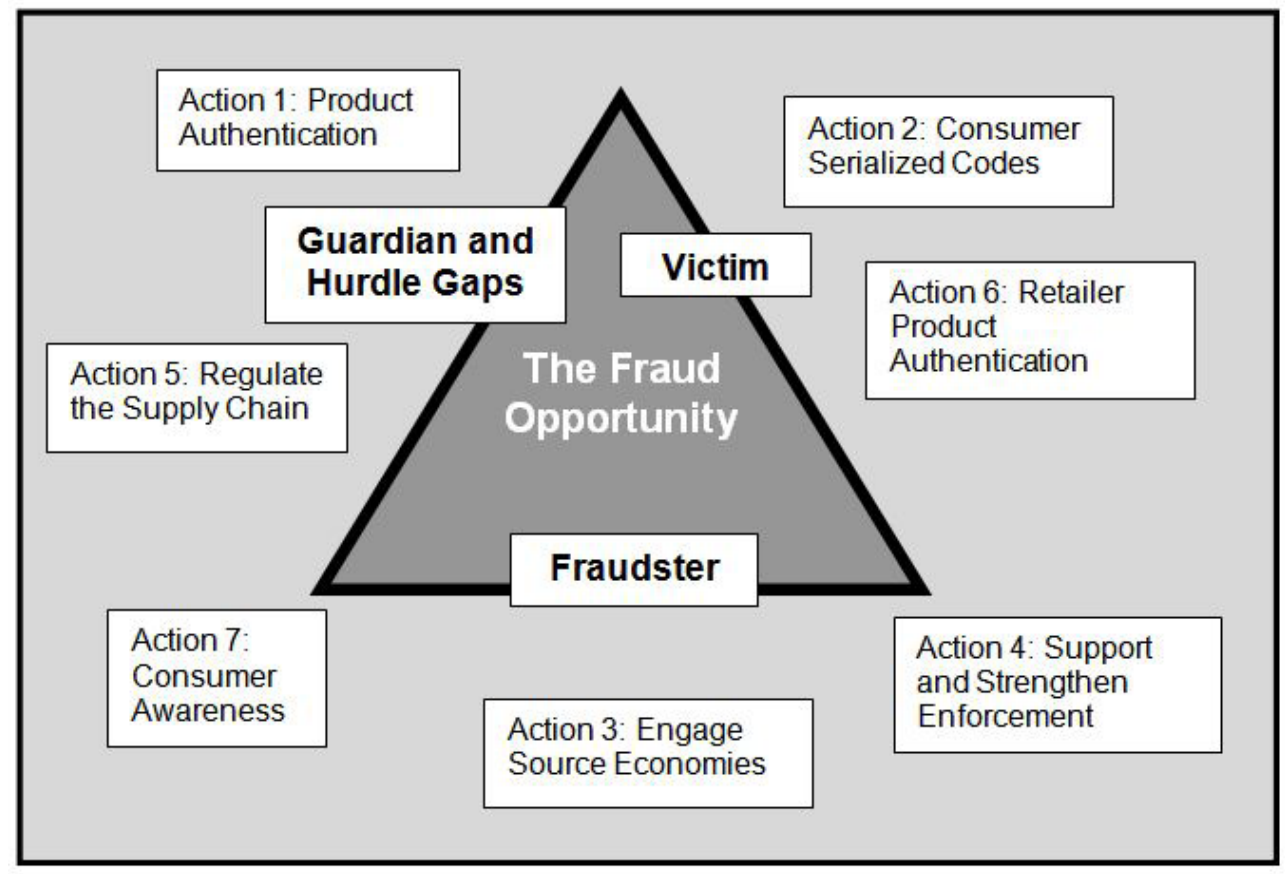

Figure 4: Application of the Crime Triangle to the Nigeria Anti-Counterfeit Initiatives-Identifying the Influence of each Action on the Fraud Opportunity

The victim side of the Crime Triangle will continue to increase as the Nigerian economy grows. In general, the demand for medicines will increase that will include higher quality, more diverse and more expensive products. The victim component of the Crime Triangle will remain important as increased consumer demand increases the fraud opportunity. Consumer awareness and education are key actions to minimize the fraud opportunity.

The fraudster side of the Crime Triangle is the most difficult to influence since there is a near infinite number of fraudsters in the world. The Nigerian focus on the source economies of fraudsters does have a deterrent effect and can continue to reduce the fraud opportunity. Also, the domestic regulation of wholesale and retail markets will further reduce the fraud opportunity by increasing barriers to potential fraudsters.

The guardian and hurdle gaps side of the Crime Triangle has been the primary focus of the NAFDAC. It continues to be the best means of reducing the fraud opportunity

In summary, utilization of Situational Crime Prevention, and the Routine Activities Theory of the Crime Triangle, provides a method to categorize and assess both the risk and the countermeasures to reduce the fraud opportunity. It is critical to understand that the chemistry of the crime and the fraud opportunity are dynamic and continually evolve. The fraud opportunity will continue to expand and grow with the Nigerian economy and as technology advances. 


\section{Discussion}

When considering the fight against SSFFC medicines, it is time for the discipline of public health and health care professionals fully integrate behavioral sciences and criminology. This broader view of the risk to human health is beginning to be embraced globally by agencies and organizations. This approach will help to focus scientific research as well as develop a methodology to create more effective countermeasures and actions.

By continuing a holistic and all-encompassing study that includes criminology, there can be an efficient and effective plan that focuses simultaneously on detection, deterrence, and prevention countermeasures. A key emphasis is that an anti-counterfeit strategy is akin to monitoring and treating a disease rather than curing a palliative condition - such as treating diabetes versus setting a broken bone. Addressing SSFFC requires continual surveillance and monitoring of the constantly shifting fraud opportunity [45]. As new and more complex countermeasures are implemented, it must be assumed that the fraudsters will discover or invent new ways to circumvent the system or they may seek new opportunities that are actually enabled by countermeasures. It cannot be underestimated how important it is to establish strong laws, regulations, enforcement, and establish stronger prosecution; but, since there are a near infinite number of fraudsters, authorities cannot rely upon these as a primary mechanism to reduce the fraud opportunity. Having laws and enforcement domestically and in source economies at least dissuades legitimate, law-abiding companies from contributing to the problem. Generally these actions work together to create an initiative that reduces the fraud opportunity.

An underlying contributor of the fraud opportunity is based on several medicines affordability and price margin issues [64,76,94]. For example, socio-economic factors may force poorer consumers to intentionally or unintentionally take more risks when by buying medicines from less regulated markets. There are also concerns regarding the fraud opportunity based on the profit margins of medicines. For example, WHO estimates product mark-ups in Nigeria, in part due to tariffs, is from 180\% to 900\% [94]. This grows a fraud opportunity because, generally, parallel trade and diversion, which grow the fraud opportunity, is economically viable when there is a mere $20 \%$ discrepancy in prices between markets or countries [21,97-99]. The WHO's Medicine Prices in Nigeria Report further states that medical procurement in Nigeria was " 2 to 64 times international reference prices" and as much as five times more expensive than in seven other regional countries [94]. A 2011 study found that substandard medicines in 17 low- and medium-income countries - including Nigeria -- were priced about $16 \%$ lower than authentic medicine [64]. The study also revealed that the price discrepancy between passing and failing drugs widened - the less expensive medicines have a higher failure rate. These issues all contribute to an increasing fraud opportunity.

Another major concern is how long the Nigerian government will continue to fund these programs. Currently the financial return on the investment for actions appears to be justified when considering the tax revenue growth from legitimate products and the growth of domestic markets for medicine manufacturing and sales. Each anti-counterfeiting countermeasure has a unique incremental benefit that, in combination, strengthens the entire system. The overall benefits include increased public health, a growing pharmaceutical manufacturing base, and reduced opportunity for crime. Analysis should not focus on which of the current anti-counterfeiting countermeasures to keep but on what additional actions should be taken to further reduce the fraud opportunity.

This assessment shifts the question from "which countermeasures to keep" to a future review of "what additional countermeasures will further reduce the fraud opportunity."

There are real business and political motives for Nigeria to continue their fight against SSFFC medicines. The increasing trust of the Nigerian citizens in their medicine supply reflects increased trust in the government. This underlying confidence helps support the stabilization and modernization of the economy and society. It is not clear if the fraudulent medicines have been simply reduced by countermeasures or if the fraudsters have dispersed to less defended countries.

\section{Conclusion}

The Nigerian combating counterfeit medicines initiative demonstrated a country's actions to combat counterfeit and substandard medical products has potential crime scene investigation and forensic science application to other countries or geographic regions experiencing similar difficulties. Forensic Science and Criminology theory can provide a new way of framing or thinking about this complex public health issue. Particularly relevant are observations regarding economic, social, and political factors that enable or inhibit countermeasures. In addition, this type of review provides real-world application of well-respected criminology theory, which is typically unconventional for public health professionals. While there should be more research before reaching additional conclusions, a country's willingness to combat counterfeit and sub-standard medicines may be an indicator of modernization and the stabilizing of a country.

The Nigerian government and the NAFDAC have demonstrated persistence and diligence by their actions, but challenges remain for the country and the ministry of health. The Nigerian SSFFC medicine initiative was studied to demonstrate how public health science can be integrated with business and political systems. The lessons learned in Nigeria can be applied to other Sub-Sahara African nations and other modernizing countries to increase public health. 


\section{Acknowledgments}

This work was conducted under the general key job responsibilities of our faculty positions. This project was not funded in any way by any agency, association, or company. Through public meetings and conferences the authors have had interaction with many agencies, associations, and companies including those mentioned in this paper.

\section{References}

1. Spink J (2012) Foreword, in Counterfeit Medicines: Detection, Identification and Analysis. Wertheimer AIW, Perry G, Editor. ILM Publications: London, UK.

2. Rudolf PM, Bernstein IBG (2004) Counterfeit Drugs. N Engl J Med 350: 1384.

3. World Health Organization (2007) Counterfeit medicines.

4. Nigerian Crusader Against Counterfeit Drugs Receives Human Rights Award In U.S. (2011) The Culvert Chronicles Laurelton, NY, United States, 15.

5. Wadman M (2008) Fake drugs: lessons for the world. Nature 452: 924.

6. Africa’s new Number One; Nigeria (2014) The Economist Intelligence Unit: London 12-n/a.

7. Step change; Nigeria's GDP (2014) The Economist Intelligence Unit: London 71-n/a.

8. World Health Organization (2014) Third Meeting of the Member State Mechanism on Substandard/ Spurious/ Falsely-Labelled/ Falsified/ Counterfeit Medical products (SSFFC) - Provisional Agenda, 10 October 2014, Geneva, 29-31.

9. World Health Organization (2009) International Medical Products Anti-Counterfeiting Taskforce - IMPACT.

10. INTERPOL (2012) INTERPOL-Europol operation results in global seizures of fake and illicit food- OPSON II.

11. US Food and Drug Administration (2010) Guidance for Industry, Standards for Securing the Drug Supply Chain - Standardized Numerical Identification for Prescription Drug Packages, FINAL GUIDANCE. U.S. Department of Health and Human Services, Food and Drug Administration, Office of the Commissioner (OC), Center for Drug Evaluation and Research (CDER), Center for Biologics Evaluation and Research (CBER), Office of Regulatory Affairs (ORA).

12. US Food and Drug Administration (2006) Counterfeit Drug Task Force Report: 2006 Update. US Food and Drug Administration: Rockville MD 20857.

13. Council of Europe (2006) Counterfeit Medicines: Survey Report. International Documents Collection, ed. Harper J Strasbourg: Council of Europe Publications.

14. World Health Organization (2011) Working Group of Member States on Substandard/ Spurious/ Falsely-Labelled/ Falsified/Counterfeit Medical Products, Provisional agenda item 5, WHO's role in the prevention and control of medical products of compromised quality, safety and efficacy such as substandard/ spurious/ falsely-labeled/ falsified/ counterfeit medical products. WHO Geneva.

15. World Health Organization (2012) WHO's role in the prevention and control of medical products of compromised quality, safety and efficacy such as substandard/ spurious/falsely labelled/ falsified/counterfeit medical products (SSFFC), Working Group of Member States on A/SSFFC/WG/3 Rev.1, Provisional agenda item 5, , 17 February 2011.

16. Orhii P (2012) Protecting the Supply Chain in Nigiera. U.S. Pharmacopeia: Rockville, Maryland. Presentation.

17. Orhii P (2010) Progress and Policy at NAFDA, in 5th Global Forum on Pharmaceutical Anti-Counterfeiting. Reconnaissance International: Miami.

18. Speiera C, Whippleb JM, Clossc DJ, Voss MD (2011) Global supply chain design considerations: Mitigating product safety and security risks. J Operations Management 29: 721-36.

19. Liang BA (2006) Fade to black: Importation and counterfeit drugs. Am J Law Med 32: 279-323.

20. World Trade Organization (1994) Agreement on Trade Related Aspects of Intellectual Property Rights, Including Trade in Counterfeit Goods.

21. deKieffer D (2006) Trojan drugs: counterfeit and mislabeled pharmaceuticals in the legitimate market. Am J Law Med 32: 325-49.

22. US Federal Bureau of Investigation (2013) Today's FBI - Facts \& Figures - 2013 to 2014, Report. Facts Figures.

23. Organization for Economic Co-operation and Development (1998) The Economic Impact of Counterfeiting.

24. European Commission (2006) Summary of Communicy Customs Activities on Counterfeit and Piracy, Results at the European Border - 2006, European Commission - Taxation and Customs Union (EC/TCU), Editor.

25. US Federal Bureau of Investigation (2005) Financial Crimes Report to the Public. Financial Crimes Section, Criminal Investigative Division, U. S. Department of Justice.

26. Wright R (2007) Developing effective tools to manage the risk of damage caused by economically motivated crime fraud. J Financial Crime $14: 17$.

27. PriceWaterhouseCooper (2007) Economic Crime: People, Culture and Controls. The 4th biennial Global Economic Crime Survey Investigations and Forensic Services, PriceWaterhouseCooper.

28. U.S. Government Accountability Office (2009) Seafood Fraud - FDA Program Changes and Better Collaboration among Key Federal Agencies Could Improve Detection and Prevention.

29. International Standards Orgaznization (2010) Home Page, Technical Committee 247 (TC 247), Fraud Countermeasures and Controls.

30. International Standards Orgaznization (2011) ISO 12931 - Performance criteria for authentication solutions for anti-counterfeiting in the field of material goods.

31. U.S. Government Accountability Office (2011) Food and Drug Administration, Better Coordination Could Enhance Efforts to Address Economic Adulteration and Protect the Public Health, in Report to Congressional Requesters GAO-12-46.

32. Spink J, Moyer DC (2011) Defining the Public Health Threat of Food Fraud. J Food Sci 76: R157-162.

33. Spink J (2011) The Challenge of Intellectual Property Enforcement for Agriculture Technology Transfers, Additives, Raw Materials, and Finished Goods against Product Fraud and Counterfeiters. J Intellectual Property Rights 16: 183-93.

34. Spink J, Fejes Z (2012) A review of the economic impact of counterfeiting and piracy methodologies and assessment of currently utilized estimates. Int J Comp Appl Crim Justice 36: 249-71. 
35. U.S. Government Accountability Office (2010) Intellectual Property -- Observations on Efforts to Quantify the Economic Effects of Counterfeit and Pirated Goods (GAO-10-423).

36. Spink J (2007) AntiCounterfeit Packaging Strategy: Aligning Actions with the Type of Counterfeiters and Type of Counterfeiting, in 23rd IAPRI Symposium on Packaging Windsor, UK.

37. Spink J (2009) Analysis of counterfeit risks and development of a counterfeit product risk model. Michigan State University: United States - Michigan 195.

38. Cohen LE, Felson M (1979) Social change and crime rate trends: A routine activity approach. American Sociological Association 588-608.

39. Felson M, Clarke RV (1998) Opportunity Makes the Thief: practical theory for crime prevention. Police Research Series Paper 98 London: Home Office.

40. Felson M, Boba R (1998) Crime and Everyday Life. 2nd ed, Thousand Oaks, Calif: Pine Forge Press.

41. Clarke RV, Eck JE (2005) Crime analysis for problem solvers. Washington, DC: Center for Problem Oriented Policing.

42. Clarke RV (1997) Situational Crime Prevention, Chapter 1. Introduction, in Situational Crime Prevention, Harrow and Heston Publishers: Guilderland, NY.

43. Eck J (1993) The Threat of Crime Displacement. Center for Problem Oriented Policing 6.

44. Heinonen J (2010) Measuring How Much Criminologists Know About Crime: Using Environmental Criminology to Assess Our Knowledge of Crime Events in Criminal Justice. University of Cincinnati: Cinninnati.

45. Spink J (2012) Overview of the Selection of Strategic Authentication and Tracing programs, chapter 9, in Identification and Analysis of Counterfeit and Substandard Pharmaceuticals, Wertheimer AI and Park PG, Editors, ILM Publications, Division of International Labmate Limited: London 154.

46. Beware the wristband con (2005) The Guardian (London) - Final Edition, June 11, 2005, Guardian Home Pages1, Hugh Muir 2005.

47. deKieffer D (2006) Trojan drugs: counterfeit and mislabeled pharmaceuticals in the legitimate market. Am J Law Med 32: 325-49.

48. Hollis ME, Felson M, Welsh BC (2013) The capable guardian in routine activities theory: A theoretical and conceptual reappraisal. Crime Prevention Community Safety 15: 65-79.

49. Hollis ME, Wilson J (2014) Who are the guardians in product counterfeiting? A theoretical application of routine activities theory. Crime Prevention Community Safety 16: 169-88.

50. Wheatley V, Spink J (2013) Defining the Public Health Threat of Dietary Supplement Fraud. Comprehensive Reviews in Food Science and Food Safety 12: 599-613.

51. Spink J, Moyer D (2013) Understanding and Combating Food Fraud. Food Technol 67: 6.

52. Everstine K, Spink J, Kennedy S (2013) Economically Motivated Adulteration (EMA) of Food: Common Characteristics of EMA Incidents. J Food Protection 76: 723-35.

53. Spink J, Moyer DC, Park H, Heinonen JA (2013) Defining the Types of Counterfeiting, Counterfeiters, and Offender Organizations. Crime Sci 2: 1-10.

54. Spink J, Moyer DC, Park H, Heinonen JA (2014) Development of a Counterfeit Incident Clustering Tool. Crime Sci 3: 1-8.

55. Heinonen J, Spink J, Wilson J (2014) When Crime Defies Classification: The Case of Product Counterfeiting. Security J doi: 10.1057/sj.2014.18.

56. Spink J (2012) Overview of the Selection of Strategic Authentication and Tracing Programmes. Counterfeit Medicines: Policy, Economics and Countermeasures 111-128.

57. Land T (2008) A Deadly Trade: A Nigerian Matriarch Wages War On Counterfeit Drugs. Contemporary Rev 290: 460.

58. Yar'Adua Calls for International Coalition Against Drug Counterfeiting (2008).

59. World Health Organization (2006) New report on corruption in health. Bull World Health Organ 84: 81.

60. Akunyili D (2007) Counterfeiting Medicines: A Serious Crime Against Humanity in European Parliament in Brussels.

61. Muanya C (2012) Ninety per cent of drugs in Nigeria are genuine, says NAFDAC survey.

62. Taylor P (2012) Nigeria says counterfeits now 5 per cent of drug market. SecuringPharma.com.

63. Bate R, Jin GZ, Mathur A (2012) Counterfeit or Substandard? The Role of Regulation and Distribution Channel in Drug Safety.

64. Bate R, Jin GZ, Mathur A (2012) Does price reveal poor-quality drugs? Evidence from 17 countries. J Health Economics 30: 1150-63.

65. World Health Organization (2011) Survey of the quality of selected antimalarial medicines circulating in six countries of sub-Saharan Africa, Quality Assurance and Safety: Medicines, Essential Medicines and Pharmaceutical Policies (WHO/EMP/QSM/2011.1,)

66. Bate R, Mathur A (2011) The Impact of Improved Detection Technology on Drug Quality: A Case Study of Lagos, Nigeria. American Enterprise Institute for Public Policy Research, ed. R. Bate.

67. Nigeria (2010) Country Loses U.S.\$325 Million to Textile Smuggling Annually. This Day (Lagos), Africa News.

68. Nigeria (2010) Nafdac Warns Fake Drug Dealers. Daily Champion (Lagos), Africa News.

69. 18 U.S.C. $\$ 2320$, US Code, III. Trafficking In Counterfeit Trademarks,Service Marks, and ertification Marks.

70. Supreme Court of the State of Florida (2003) In the supreme court of the state of florida, Case No: SC02-2645, First interim report, of the seventeenth statewide grand jury, Case No: SC02-2645, First Interim Report of the Seventeenth Statewide Grand Jury, Dec. 19, 2003.

71. Cormier JW, Kozell R, McCurdy JL (2009) Intellectual Property Crimes. American Criminal Law Review 761-1301.

72. Gogo A (2008) World First Developed in Ghana: Real-time GSM Drug Pedigree Assurance, in Presented at Technology Transformation Seminar, Ghana-India Kofi Annan Centre of Excellence in ICT. 2008.

73. Nigeria (2010) Nafdac Introduces Phone Service to Checkmate Counterfeiting. This Day (Lagos), Africa News.

74. Spink J (2009) What Role Can We Count on Consumers to Play in Authentication. Anti-Counterfeiting and Product Protection Program Paper Series 1-35.

75. Business Monitor International (2010) Nigeria Pharmaceuticals \& Healthcare Report, Q2 2010, in Nigeria Pharmaceuticals \& Healthcare Report, Business Monitor International: London, United Kingdom 1-105. 
76. Business Monitor International (2013) Nigeria Pharmaceuticals \& Healthcare Report, Q1 2013, in Nigeria Pharmaceuticals \& Healthcare Report. Business Monitor International: London, United Kingdom 1-97.

77. United Nations (2013) Total Nigerian Pharmaceutical Imports (per UN ComTrade).

78. Nigeria to sign deal to limit importation of "substandard" products from China (2009). BBC Monitoring Africa - Political.

79. NAFDAC Likely to Set Up Check Points for Counterfeit Drugs (2009) Financial Express.

80. Nigeria more vigilant against fake drugs (2009) New Delhi Indo-Asian News Service.

81. Nigeria (2010) Proper Policing at Our Border, Ports Will Reduce Fake Products Vanguard Africa News.

82. Fortin ND (2009) Food regulation: law, science, policy, and practice. Hoboken NJ: Wiley.

83. Eck JE (2004) Assessing responses to problems: An introductory guide for police problem-solvers. US Department of Justice, Office of Community Oriented Policing Services.

84. Nigeria (2009) Harsher Penalties for Peddlers of Fake Drugs. Daily Trust (Abuja), Africa News.

85. Nigeria (2010) Internet And Control of Medicines. Daily Trust (Abuja), Africa News.

86. Nigeria (2010) Nafdac Impounds N67 Million Unregistered Drugs At Seme, . Daily Champion (Lagos), Africa News.

87. Nigeria (2009) Nafdac Collaborates to Strengthen Pharmaceutical Distribution. Daily Trust (Abuja), Africa News.

88. Ogundipe S (2009) Stiffer Punishment Awaits Drug Offenders Tuesday, in Vanguard Lagos.

89. US Food and Drug Administration (2013) Prior Notice of Imported Food Shipments, Protecting the U.S. Food Supply, U.S. Food and Drug Administration, U.S. Department of Health and Human Services, The Public Health Security and Bioterrorism, Preparedness and Response Act of 2002.

90. Spink J, Helferich OK, Griggs JE (2010) Combating the Impact of Product Counterfeiting. Distribution Business Management J $10: 6$.

91. United Nations Industrial Development Organization (2011) PHARMACEUTICAL SECTOR PROFILE - Nigeria, Global UNIDO Project: Strengthening the local production of essential generic drugs in least developed and developing countries.

92. Taylor P (2010) RFID partnership aims to tackle medicine counterfeiting in Africa. Securing Pharma Newsletter.

93. Swedberg C (2010) Nigerian Drug Agency Opts for RFID Anticounterfeiting Technology. RFID J.

94. World Health Organization (2006) Medicine Prices in Nigeria 71.

95. Obinna C, Olawale G (2010) NAFDAC introduces new anti counterfeiting in Nigeria's Best Forum.

96. Ochayi C (2009) Checkmate Substandard Products, Udoh Urges FG. Vanguard (Nigeria) AAGM.

97. Uganda (2009) People Power Vs Fake Drugs. New Vision Africa News 2009.

98. Organization for Economic Co-operation and Development (2007) The Economic Impact of Counterfeiting and Piracy, Part I: Overall Assessment.

99. deKieffer D (2008) Trade Diversion as a Fund Raising and Money Laundering Technique of Terrorist Organizations, in Countering the Financing of Terrorism, Biersteker TJ, Eckert SE, Editors Routledge: New York 150-173.

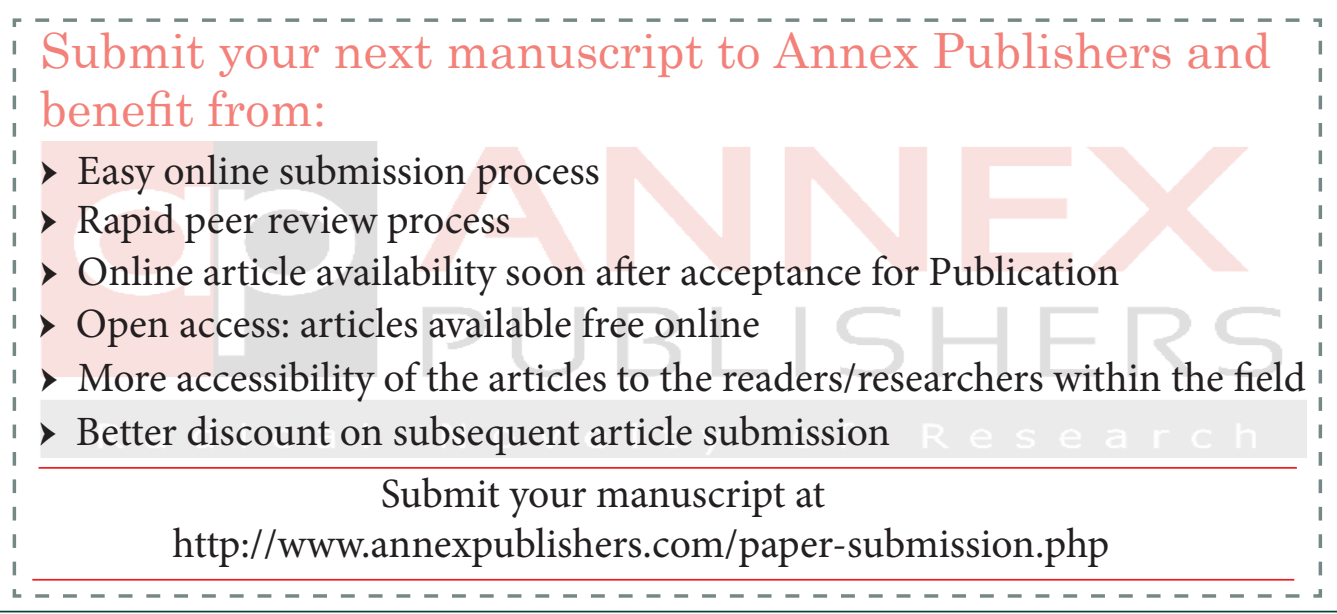

